\title{
Glucose and lipid transporters roles in type 2 diabetes
}

\author{
Valentina L Kouznetsova ${ }^{1,2 *}$, Max Hauptschein ${ }^{3 \#}$, and Igor F Tsigelny ${ }^{1-3,5 *}$ \\ ${ }^{1}$ Mores Cancer Center UC San Diego, USA \\ ${ }^{2}$ San Diego Supercomputer Center, UC San Diego, USA \\ ${ }^{3}$ Department of Neurosciences, UC San Diego, USA \\ ${ }^{4}$ REHS program UC San Diego, USA \\ ${ }^{5}$ CureMatch Inc. San Diego, USA \\ \#These authors contributed equally to this work.
}

\begin{abstract}
Type 2 diabetes is a chronic condition encompassing many metabolic processes throughout the body. Glucose and lipid transporters are involved in many of these critical metabolic processes and pathways, and are linked to the development and symptoms of type 2 diabetes. Therapeutic opportunities utilizing these transporters have already begun with the gliflozin drug class of inhibitors of sodium glucose linked co-transporters (SGLT). A range of transporter families: SLC5A (SGLT), SLC2A (GLUT), and ATP binding cassette (ABC) transporters are either connected to glucose or cholesterol homeostasis, significant in a systemic disease like diabetes type 2 . Elucidating the roles of these transporters in type 2 diabetes is vital in establishing new and effective options for treatment.
\end{abstract}

\section{Sodium glucose linked co-transporters (SGLT)}

Sodium glucose linked co-transporters (SGLT) are members of the large solute carrier family of membrane transporter proteins (SLC). The SLC family contains hundreds of members and has three main families involved in glucose transport: SLC2, SLC5, and SLC50. Specifically, the SGLT class of transporters are encoded by the SLC5 gene type. There are twelve different transporter proteins encoded by the SLC5 genes, with six of them going under the alias of SGLT. The SLC5 family (Table 1) are membrane transporters with nearly all being involved in forms of glucose transport and homeostasis, transporting sugars such as glucose, mannose, and myo inositol and located in a range of tissues such as the small intestine, kidney, heart, lung, and liver. The SLC5 family of transporters are known for transport through a sodium ionglucose co-transport mechanism. This type of transport utilizes glucose and sodium to allow glucose entry to the cell. To begin the process, initial sodium ion binding to the exterior side of the transporter protein causes a protein conformational change that allows glucose to bind to the binding site. Upon the glucose binding, the protein undergoes another change in conformation, opening the interior gate of the transporter, and thus leading to both glucose and sodium ion entry into the cell [1] (Figure 1). Out of the SLC5 family, SLC5A1 (SGLT1) and SLC5A2 (SGLT2) were most prominently associated with type 2 diabetes due to their role in a glucose reabsorption process. It is also worth noting development of new inhibitor T2DM drugs that utilize both synthetic and natural compounds inhibitors through the creation of inhibitors of SGLT 1 and 2 [2].

SGLT 1 and 2 are predominantly expressed in the small intestine and kidney, and are involved in proximal tubule glucose reabsorption (Figure 2), a process that reabsorbs glucose from the lumen, and into the cell through SGLT using an ATPase generated sodium concentration gradient. When SGLT does not reabsorb the glucose, it is excreted from the body, being in the urine [3]. Unlike SGLT2, SGLT1 is also expressed in various other tissues, including the liver, heart, and lungs. This should be considered when looking at possible SGLT1 inhibition options to avoid negative side effects. Less T2DM inhibitor treatments center around SGLT1 than SGLT2 because of both its wider expression and its lesser role in glucose reabsorption. SGLT2 handles the bulk of glucose absorption, $90 \%$ of filtered glucose, and has more selectivity in expression, making it the primary target for the majority of inhibitor drugs [2,4,5]. Substrates of SGLT1 include glucose, galactose, and urea, and substrates of SGLT2 include only glucose [6,7]. After absorption by SGLT, glucose exits the cell through solute carrier family 2 facilitated glucose transport member 2 (GLUT2), entering the bloodstream and increasing blood glucose concentration ${ }^{2}$ (Figure 2). In type 2 diabetes mellitus (T2DM) patients, SGLT1 was found to be increasingly expressed in certain studies. ${ }^{1,5,24}$ In addition, increased glucose uptake in cardiomyocytes following stimulation caused by insulin and leptin signaling illustrates how insulin and leptin may be partly responsible for either SGLT1 expression or translocation to the membrane, as well as increased glucose uptake activity [6,7]. Two laboratories reported partially contradicting results in SGLT1 kidney tissue expression, with the first [8] identifying that SGLT1 expression in T2DM patients is higher than in control patients and the second reporting the same or lower expression of SGLT1/2 and GLUT1/2 when the T2DM patients were compared to the control patients. Both laboratories results on SGLT2, GLUT1, and GLUT2 expression generally correspond to each other, but further discrepancies are noted. For example, one possible explanation of these differences may be the method of acquisition and type of kidney tissue used in the studies, as the first study obtained the tissue from biopsies [8] and the second

Correspondence to: Igor F Tsigelny, Mores Cancer Center UC San Diego, UCSD, 9500 Gilman Dr., La Jolla, CA 92093-0505, USA, E-mail: itsigeln@ucsd.edu

Received: October 17, 2017; Accepted: November 23, 2017; Published: November 27, 2017 
Table 1. SLC5 (SGLT) Transporter Family.

\begin{tabular}{|c|c|c|c|c|}
\hline Transporter Name & Function & Substrate & Location & References \\
\hline SGLT1 (SLC5A1) & $\begin{array}{l}\text { Involved in proximal tubule glucose } \\
\text { reabsorption through transportation } \\
\text { of glucose from the lumen into the } \\
\text { cell. Expressed in wider variety of } \\
\text { tissues. }\end{array}$ & Glucose, galactose, urea & Intestine, kidney, liver, heart, lungs & $1,4,29$ \\
\hline SGLT2 (SLC5A2) & $\begin{array}{l}\text { Involved in proximal tubule } \\
\text { glucose reabsorption like SGLT1. } \\
\text { Commonly inhibited in T2DM } \\
\text { treatment. }\end{array}$ & Glucose & Intestine, kidney & $1,4,29$ \\
\hline SGLT3 (SLC5A4) & $\begin{array}{l}\text { May be involved in glucose sensing, } \\
\text { does not transport glucose. }\end{array}$ & Sodium ions, hydrogen ions & $\begin{array}{l}\text { Small intestine, skeletal muscle, } \\
\text { kidney, uterus and testis }\end{array}$ & 1,4 \\
\hline SGLT4 (SLC5A9) & $\begin{array}{l}\text { May be involved in mannose } \\
\text { homeostasis along with transport } \\
\text { of glucose. }\end{array}$ & Mannose, fructose, glucose & $\begin{array}{l}\text { Kidney, small intestine, brain, } \\
\text { kidney, liver, heart, uterus and lung }\end{array}$ & $1,4,29$ \\
\hline SGLT5 (SLC5A10) & $\begin{array}{l}\text { Involved in sodium dependent } \\
\text { glucose transport along with its } \\
\text { other substrates. }\end{array}$ & Mannose, fructose, glucose & Kidney cortex & 1,4 \\
\hline SGLT6 (SLC5A11) & $\begin{array}{l}\text { Does not transport glucose, } \\
\text { expression is found throughout the } \\
\text { body. }\end{array}$ & Myo-inositol, chiro-inositol & $\begin{array}{l}\text { Thyroid, brain, heart, muscle, } \\
\text { spleen, liver, lung. }\end{array}$ & $1,4,29$ \\
\hline
\end{tabular}

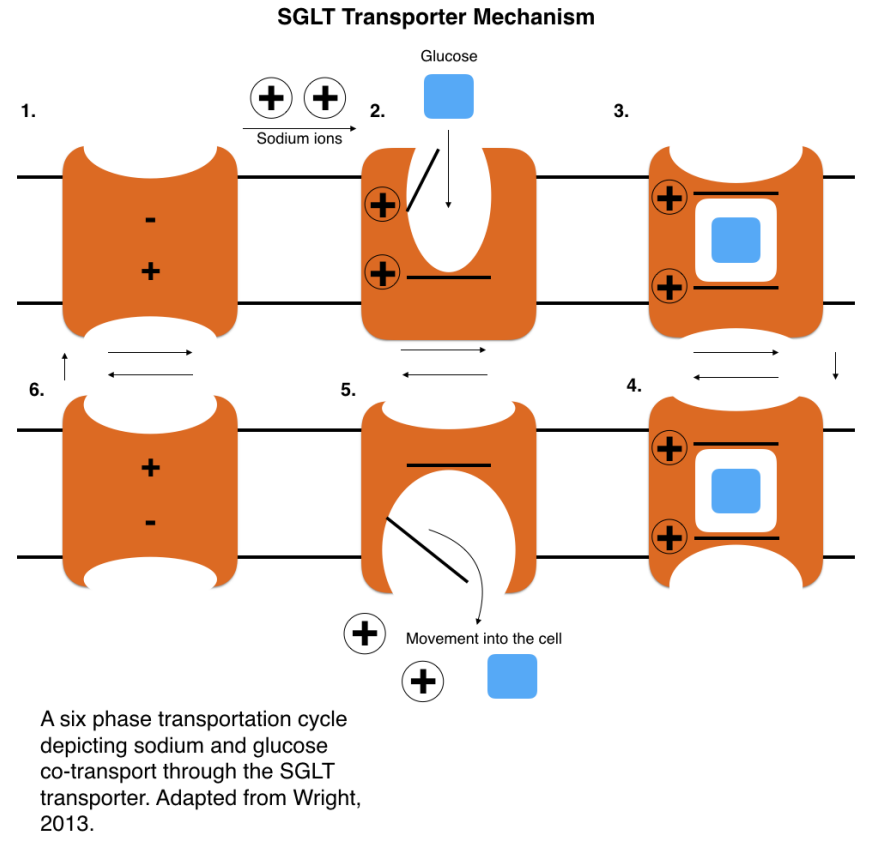

Figure 1. Mechanism of SGLT sodium ion glucose cotransport. (Adapted from Wright) [29].

study obtained tissue from patients with renal cancer undergoing a unilateral nephrectomy [9]. Both of these studies sampled kidneys that were in the healthy range of the estimated glomerular filtrate rate (GFR) scale. Furthermore, a different laboratory [10] reported diseased tissue in diabetic patients, with GFRs in the diseased range, to have higher expression of SGLT2, contrasting the laboratories that reported no significant change in SGLT2 expression in general T2DM kidney tissue $[8,9]$. The expression of these transporters in certain animals also gives varied results compared to human expression tests, as GLUT2 was found to be overexpressed in T2DM rats [11]. Therefore, the precise renal expression trends of SGLT1/2 and GLUT1/2 remain mostly unclear, though two of the reports from the more recent studies $[8,9]$ have been consistent regarding SGLT2 and GLUT1/2 expression. Hence, Factors such as species, kidney tissue type, and method of data collection should be considered in future studies in order to get more consistent and accurate expression results. This would ultimately help

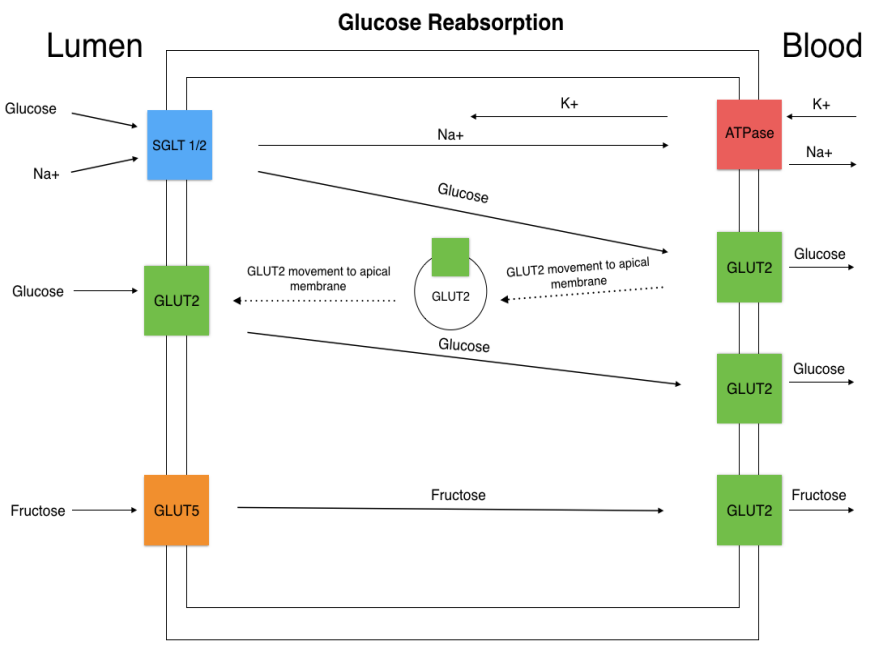

Glucose reabsorption process illustrating

SGLT and GLUT2 dynamics as well as

fructose absorption through GLUT5.

Adapted from Mather et al., 2011.

Figure 2. SGLT transport dynamics and glucose reabsorption. (Adapted from Mather et al.) [18].

establish the exact role T2DM plays on both SGLT expression, and the dynamics and activity of the glucose reabsorption process. Rather than expression, the activity of these transporters in T2DM patients compared to control, may also give insight to how the disease influences the renal glucose reabsorption process. Specifically, measurements on glucose influx and efflux through an assay. Data on measurements of expression of SGLT1, SGLT2, GLUT1, and GLUT2 appear to link SGLT1 and GLUT1 as similar expression, as well as SGLT2 with GLUT2 as similar expression. Intriguingly, the Norton et al., study also reported SGLT2 and GLUT2 expression correspondence, but the 4 fold increase of SGLT1 expression in T2DM recorded in the study was not followed by GLUT1 expression, whereas Solini et al. reported correspondence of both of the respective SGLT1/2 and GLUT1/2 $[8,9]$. In T2DM, the increased expression of SGLT in renal glucose reabsorption is a detriment, increasing blood glucose concentration, and furthering hyperglycemia. Inhibition of SGLT by various drugs 
and compounds therefore, is significant in restoring adequate blood glucose concentration, as it blocks glucose from reentering the bloodstream through GLUT2, increasing glucose excretion from the kidney. Phlorizin, a competitive inhibitor of SGLT, was discovered and followed by synthetic chemical analogs in the gliflozin class, which all reduce blood glucose levels in T2DM [3]. However, the general effect of SGLT inhibitor drugs is reportedly limited to only a $30-50 \%$ reduction of renal glucose reabsorption activity, indicating how more knowledge on the dynamics of SGLT and the reabsorption process as a whole is needed [12]. Understanding how expression and activity of the SGLT and GLUT absorption pathway is altered in T2DM may be crucial in finding more effective treatments.

\section{Glucose transporter/SLC2 (GLUT) family}

The SLC2 (GLUT) family of transporter proteins are members of the larger SLC family of membrane transporters, and like SLC5, primarily transport glucose. The facilitated glucose transporter (GLUT) family consists of fourteen members (Table 2) that are expressed in a vast range of different tissues across the body with most involved in regulating glucose homeostasis in some form. All fourteen GLUTs have been classified into three distinct classes pertaining to the location and function of each and are encoded by the SLC2 type genes. The GLUT family also carries a variety of substrates apart from glucose, including GLUT5 transportation of fructose and GLUT9 transportation of urate, as well as other sugars such as fructose, mannose, and myo inositol $[13,14]$. Recently identified members of the family such as GLUT 13 and GLUT 14, have less known structures and specific functions, and therefore, the role of each in the systemic disease of T2DM is unclear. Others such as GLUT2 and GLUT4 have a more solidified role in T2DM, playing part in known metabolic processes associated with glucose homeostasis. Many of the SLC2 transporters seem to be vital in importing glucose into the cell and lowering hyperglycemia, but function may differ depending on which tissues they are expressed in. Overall, the more known GLUTs should be further investigated for involvement in T2DM due to the significant participation that most of them have in glucose homeostasis. The structure and specific properties of the lesser known, and more recently discovered GLUTs can be further studied to determine if any have a more explicit role in the development and symptoms of T2DM.

Since GLUTs are widely expressed in different tissues and play roles in glucose homeostasis, they are of significance in glucose metabolic dysfunction in T2DM. A portion of the GLUTs, most notably GLUT15 , were increasingly studied than others, and therefore, some GLUTs are known to be involved with diabetes, while the roles of others are less known. For example, GLUT4 has been widely studied, and its involvement in T2DM has been demonstrated. ${ }^{6}$ GLUT4 is most known for its responsiveness to insulin signaling through the insulin receptor in the membrane, and therefore, GLUT4 has a critical role in overall glucose homeostasis in the body (Figure 3). GLUT4 is primarily expressed in adipose tissue, skeletal muscle, and cardiac muscle, and transports glucose and glucosamine. Insulin signaling ultimately triggers GLUT4 vesicle translocation to the membrane through a process that begins with insulin binding to the insulin receptor (IR) and subsequently increasing glucose transportation into the cell. After insulin binds to the insulin receptor, insulin receptor substrate 1 (IRS-1) is activated through phosphorylation by the IR, thus leading to activation of the kinases: phosphoinositide 3-kinase (PI3K) and protein kinase B (AKT), initiating the GLUT4 vesicle translocation (Figure 3) [15]. A defect in the insulin receptor or insulin signaling could lead to improper translocation of GLUT4 and increased blood glucose concentration in T2DM $[3,13,14,16]$. Furthermore, stimulating up regulation of GLUT4 in the muscle to increase glucose uptake to the cell could serve as a potential therapeutic option as noted in a recent study showing lower hyperglycemia in mice due to the increased

Table 2. SLC2 Transporter Family.

\begin{tabular}{|c|c|c|c|c|}
\hline Transporter Name & Function & Substrate & Location & References \\
\hline GLUT1 (SLC2A1) & $\begin{array}{l}\text { Membrane transporter of glucose } \\
\text { for glucose uptake into the cell }\end{array}$ & $\begin{array}{l}\text { Glucose, galactose, mannose, } \\
\text { glucosamine }\end{array}$ & Erythrocytes, endothelial, placenta & $1,6,7$ \\
\hline GLUT2 (SLC2A2) & $\begin{array}{l}\text { Involved in proximal tubule } \\
\text { glucose reabsorption into the } \\
\text { bloodstream. Can be translocated to } \\
\text { the apical membrane with SGLT. }\end{array}$ & $\begin{array}{l}\text { Glucose, galactose, fructose, } \\
\text { mannose, glucosamine }\end{array}$ & Liver, intestine, kidney & $1,6,7$ \\
\hline GLUT3 (SLC2A3) & $\begin{array}{l}\text { Primarily responsible for glucose } \\
\text { uptake in neurons. }\end{array}$ & $\begin{array}{l}\text { Glucose, galactose, mannose, } \\
\text { xylose }\end{array}$ & Brain, testis & $1,6,7$ \\
\hline GLUT4 (SLC2A4) & $\begin{array}{l}\text { Insulin responsive glucose } \\
\text { absorption into the cell through } \\
\text { insulin receptor signaling pathway. }\end{array}$ & Glucose, glucosamine & Adipose, skeletal muscle & $1,6,7$ \\
\hline GLUT5 (SLC2A5) & Fructose transport. & Fructose & Small intestine, kidney & $1,6,7$ \\
\hline GLUT6 (SLC2A6) & $\begin{array}{l}\text { Primarily expression in the brain } \\
\text { and spleen. }\end{array}$ & Glucose & Brain, spleen, leucocytes & $1,6,7$ \\
\hline GLUT7 (SLC2A7) & $\begin{array}{l}\text { Transports both glucose and } \\
\text { fructose. }\end{array}$ & Glucose, fructose & $\begin{array}{l}\text { Small intestine, colon, testis, } \\
\text { prostate }\end{array}$ & $1,6,7$ \\
\hline GLUT8 (SLC2A8) & $\begin{array}{l}\text { High expression in testis, glucose } \\
\text { may not be main substrate. }\end{array}$ & Glucose, fructose, galactose & $\begin{array}{l}\text { Testis, brain, adrenal gland, liver, } \\
\text { spleen, brown adipose tissue, lung }\end{array}$ & $1,6,7$ \\
\hline GLUT9 (SLC2A9) & Mainly known for urate transport. & Urate, glucose, fructose & Liver, kidney, small intestine & $1,6,7$ \\
\hline GLUT10 (SLC2A10) & $\begin{array}{l}\text { Possible association to T2DM based } \\
\text { on chromosome location. }\end{array}$ & Glucose, galactose & $\begin{array}{l}\text { Liver, kidney, pancreas, skeletal } \\
\text { muscle }\end{array}$ & $1,6,7$ \\
\hline GLUT11 (SLC2A11) & $\begin{array}{l}\text { Noted to have similar homology to } \\
\text { GLUT5 }\end{array}$ & Glucose, fructose & Heart, muscle & $1,6,7$ \\
\hline GLUT12 (SLC2A12) & $\begin{array}{l}\text { Possible insulin responsive glucose } \\
\text { transporter. }\end{array}$ & Glucose & Skeletal muscle, heart, placenta & $1,6,7$ \\
\hline GLUT13 (SLC2A13) & $\begin{array}{l}\text { Myo-inositol transporter, critical } \\
\text { to various signal pathways in the } \\
\text { brain. }\end{array}$ & Myo-inositol & Brain, adipose & $1,6,7$ \\
\hline GLUT14 (SLC2A14) & Possible homology to GLUT3. & Glucose & Testis & $1,6,7$ \\
\hline
\end{tabular}




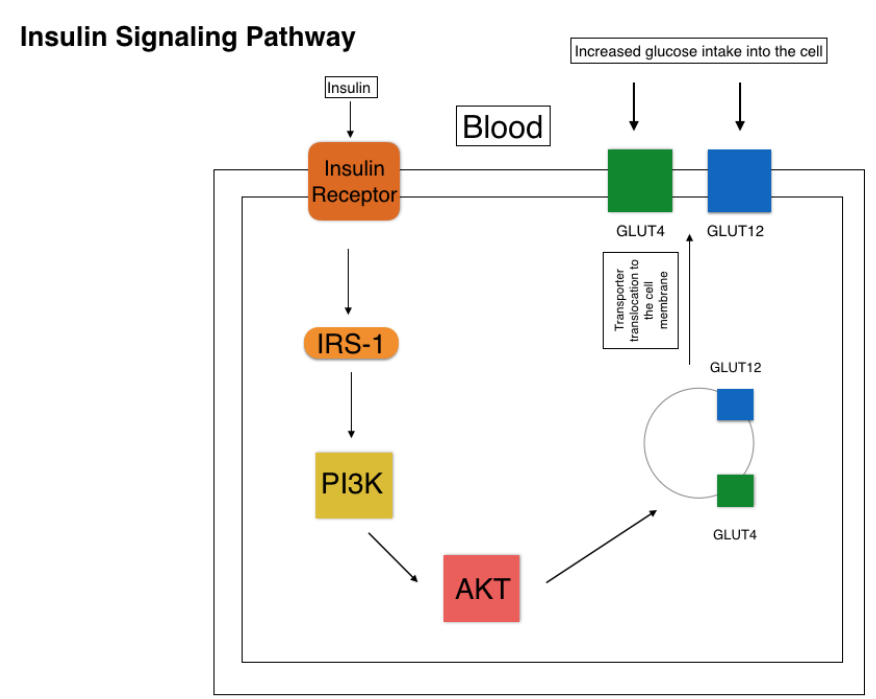

Insulin signaling pathway leading to GLUT4 and possibly GLUT12 translocation to the cell membrane and increased glucose intake into an insulin responsive cell. Adapted from Vallaghe et al., 2016.

Figure 3. Simplified version of insulin signaling leading to GLUT4 vesicle translocation to the membrane. (Adapted from Vallaghe et al.) [30]

expression and activity of GLUT4 [17]. GLUT4 involvement in insulin signaling pathways could be further studied to find new therapeutic options for T2DM. GLUT2 is expressed in the liver, intestine, kidney, and brain and transports glucose, galactose, fructose, mannose, and glucosamine $[13,14,17]$. Down regulation of GLUT2, which can be viewed as beneficial in T2DM due to the role of GLUT2 in absorbing glucose into the bloodstream in cofunction with SGLT, leads to lower hyperglycemia in the livers of mice. Overall the beneficiary effects of lower expression of GLUT2 and higher expression of GLUT4 in certain tissue were demonstrated in T2DM cases [17]. It has been noted that in intestinal cells, GLUT2 can be translocated to the apical membrane with SGLT for glucose absorption depending on the amount of glucose present and SGLT activity (Figure 2). GLUT2 movement to the apical membrane may be concerted with insulin signaling. Therefore, insulin resistance in T2DM would lead to increased and less regulated GLUT2 translocation to the apical membrane and glucose absorption, causing higher hyperglycemia in T2DM cases $[13,18]$. There exists a correlation between fructose consumption through food and T2DM occurrence, and fructose transporter GLUT5 may also play a role in the development of T2DM. GLUT5 uses active transport to intake fructose into the intestinal cell where it gets retransported into the blood through GLUT2, similar to SGLT transport [19]. GLUT5 most notably transports fructose and is primarily expressed in the small intestine and kidney. In T2DM patients, GLUT5 is increasingly expressed in its primary tissues: the intestine and kidney. Further research is needed to elucidate a direct and specific correlation between the development of T2DM and GLUT5 [13,14]. GLUT12, a transporter of glucose primarily expressed in skeletal muscle, fat, heart, prostate, and placenta tissue, has been suggested as a possible insulin responsive glucose transporter, similar to GLUT4 in the insulin responsive tissues of skeletal muscle and fat. Therefore, GLUT12, like GLUT4, could become potentially critical to T2DM treatment in order to increase glucose uptake into the cell and reduce hyperglycemia. GLUT12 transporter mechanisms of action still need further study, including the degree to which its pathway is related to that of GLUT4 $[13,20]$. Another study appears to contradict the insulin responsive properties of GLUT12, finding that it does not respond to insulin in cardiomyocytes, but may do so in other tissues [21]. GLUT10 has been observed as a potential candidate involved in T2DM development due the SLC2A10 gene location on chromosome region 20q12-q13.1, a prime T2DM gene risk target. However, a lack of studies confirming GLUT10 as a significant T2DM risk makes it less of a focus and concern in future T2DM treatment [22].

\section{ATP binding cassette (ABC) transporters}

Adenosine triphosphate binding cassette $(\mathrm{ABC})$ transporters are a large family of transporters with around 49 members ranging through seven subfamilies that cover ABCA through ABCG. These transporters carry a wide range of different substrates of both small and larger molecules, and are involved in a variety of different bodily processes, unlike the more selective different ATPase proteins that cover increasingly smaller ranges of substrates. The ABC family of transporters are involved in both cellular importation and exportation, which accounts for some of the characteristics that separate them into subfamilies. A portion of the $\mathrm{ABC}$ transporters are involved in cholesterol and lipid homeostasis and transport, proving them significant in the development of atherosclerosis. Since atherosclerosis induced heart disease and heart failure is significantly increased in type 2 diabetes, the lipid and cholesterol transporters of the $A B C$ family may be significantly linked to T2DM related heart problems. Both genes ABCA1 and ABCG1 role in cholesterol efflux in macrophages to high density lipoproteins are critical in reducing risk of heart disease (Table 3). Furthermore, studies have linked mutations and defects in these genes to T2DM patients, signaling the crucial role of the genes in patients affected by T2DM because of the risk caused by their dysfunction $[23,24]$.

ABCA1 transports cholesterol and phospholipids. ABCG1 transports cholesterol and oxysterol. ABCA1 and ABCG1 have roles in the process of cellular cholesterol and phospholipid efflux, leading to the formation of high density lipoproteins (HDL). HDLs are found predominantly in the liver and intestine, and are critical to cholesterol removal from the cell to prevent blockage and excess buildup. Both the ABCA1 and ABCG1 transporters are primarily responsible for excess cholesterol transportation out of the cell [23]. Lower amounts of HDLs are correlated with heart disease risk and atherosclerosis due its role in excreting excess cholesterol, a risk further accentuated in T2DM. The nuclear liver X receptor (LXR) regulates cholesterol efflux activity through ABCA1 and ABCG1 expression in macrophages (Figure 4). Stimulating LXR increases the expression of ABCA1 and $A B C G 1$ by increasing transcription rates, therefore increasing the cholesterol efflux function of the transporters. It is noted that oxysterols act as agonists for LXR, and other synthetic agonists have proven effective [24]. ABCG1 expression was found to be reduced in T2DM patients [25]. This leads to limited cholesterol efflux from macrophages to HDLs and an accumulation of excess cholesterol in the cell and in veins, causing a higher risk of heart disease and failure in T2DM patients due to the excess cholesterol buildup of low density lipoproteins (LDL). Increasing expression of ABCA1 and ABCG1 are noted as possible therapeutic targets in increasing cholesterol efflux and reducing cholesterol intracellular buildup in T2DM. LXR agonists are noted as a potential treatment, but the lack of isoform specific synthetic agonists for LXR, makes finding a proper treatment less clear [25]. Mutations to ABCA1 gene appear to be found more prominently in many T2DM patients, and serve as evidence that ABCA1 plays a protective role against diabetes and heart disease through its role in 
Table 3. ABC Transporter Family.

\begin{tabular}{|c|c|c|c|c|}
\hline Transporter Name & Function & Substrate & Location & References \\
\hline ABCA1 & $\begin{array}{l}\text { Involved in macrophage cholesterol } \\
\text { and lipid efflux to HDLs. }\end{array}$ & Cholesterol, phospholipids & $\begin{array}{l}\text { Endothelial, macrophages, liver, } \\
\text { intestine, adipose }\end{array}$ & 12 \\
\hline ABCG1 & $\begin{array}{l}\text { Involved in macrophage cholesterol } \\
\text { and lipid efflux to HDLs. }\end{array}$ & $\begin{array}{l}\text { Cholesterol, phospholipids, } \\
\text { oxysterol }\end{array}$ & $\begin{array}{l}\text { Macrophage, adipose, lung, } \\
\text { intestine }\end{array}$ & 12 \\
\hline
\end{tabular}

\section{Cholesterol Efflux}

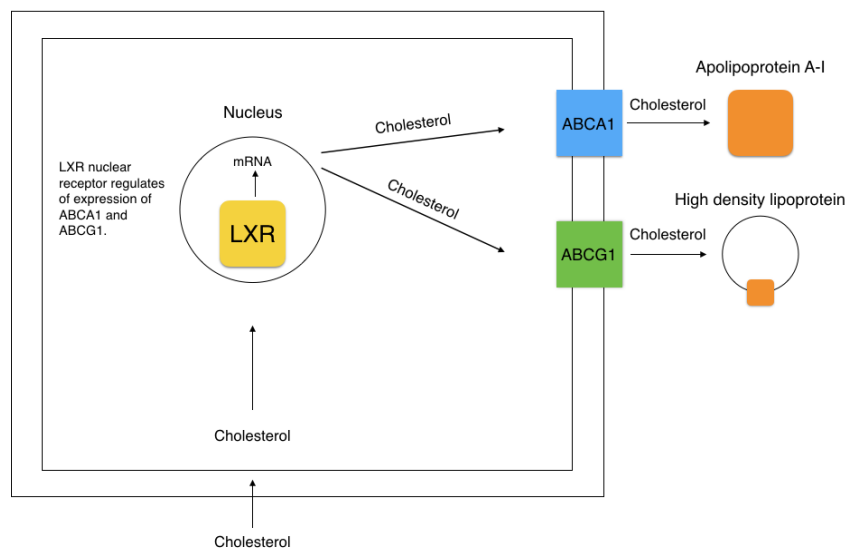

Cholesterol efflux through $\mathrm{ABCA} 1$ and

ABCG1 towards the formation of high

density lipoproteins in macrophages.

Adapted from Radar, 2006.

Figure 4. Cholesterol efflux in macrophage through ABCA1 and ABCG1. (Adapted from Radar, 2006) [12].

excess cholesterol efflux, as diabetic patients are more prone to excess cholesterol. Many of these mutations are described as clustered "in the extracellular loops, the NBD domains, and the C-terminal region" [26]. Defects and lower expression of both ABCA1 and ABCG1 would lead to reduced excess cholesterol transportation and formation of HDLs, therefore increasing the risk of heart failure in T2DM patients. Though ABCA1 and ABCG1 correlation with heart disease risk in T2DM is known, their possible connection to the direct development and pathogenesis of T2DM raises more questions. Multiple populations that experience a high frequency of T2DM cases, have an increased occurrence of the $\mathrm{R} 230 \mathrm{C}$ polymorphism in the ABCA1 gene, linked to lower HDL, highlighting the significance of this gene in regulating the formation of HDLs. Whether this polymorphism, or any defect that lowers the gene expression, directly causes T2DM or is a product of the disease it not clear. One possibility noted, is that lower expression and activity of the two ABC genes may be caused by hyperglycemia in T2DM. Though unproven, the point is supported by expression levels of ABCA1 inversely comparing to expression levels in leukocytes of glucose deprived fasting individuals without T2DM or hyperglycemia [26-28]. An analysis of a Mexican population with T2DM indicated single nucleotide polymorphisms (SNP) in ABCA1 associated with those with T2DM, with a dbSNP location of rs9282541, as well as four other locations in the analysis [29]. In another T2DM population, common SNPs in ABCA1 were linked to lower HDL-C levels. The SNP with a dbSNP location of rs 1800978 for ABCA1 was correlated with lower HDLs and the SNP with location rs2230808 was linked to heart disease. Overall, the mutations to ABCA1 were found to be associated with HDL levels or heart disease in T2DM patients in the study [30]. Even if the genes do not directly cause T2DM, their role in heart disease risk in T2DM patients is prominent, and more research is needed to elucidate whether they do or do not actually have a role in the genesis of the disease. Understanding the pathways and functions of ABCA1 and ABCG1 is critical in addressing therapeutic options for T2DM and lowering heart disease risk for those with T2DM, due to the transporters role in creating HDLs and mediating lipid homeostasis. The defects of these genes found in T2DM patients are concerning due to the increased chance of heart disease associated with low HDLs and excess cholesterol buildup and blockage. It is also necessary to understand to what extent lower expression and mutations of the genes contribute to the development of T2DM and other risk factors [31-34].

\section{Conflict of Interests}

All the authors declare that they have no conflicts of interest with respect to the publication of this article.

\section{References}

1. Wright EM (2013) Glucose transport families SLC5 and SLC50. Mol Aspects Med 34 183-196. [Crossref]

2. Poulsen SB, Fenton RA, Rieg T (2015) Sodium-glucose cotransport. Curr Opin Nephrol Hypertens 24: 463-469. [Crossref]

3. Navale AM, Paranjape AN (2016) Glucose transporters: physiological and pathological roles. Biophys Rev 8: 5-9. [Crossref]

4. Vrhovac I, Eror D, Klessen D, Burger C, Breljak D, et al. (2014) Localizations of Na+d-glucose cotransporters SGLT1 and SGLT2 in human kidney and of SGLT1 in human small intestine, liver, lung, and heart. Pflugers Arch 467: 1881-1898. [Crossref]

5. Szablewski L (2017) Distribution of glucose transporters in renal diseases. J Biomed Sci 24: 64. [Crossref]

6. Szablewski L (2017) Glucose transporters in healthy heart and in cardiac disease. Int J Cardiol 230: 70-75. [Crossref]

7. Banerjee S, McGaffin K, Pastor-Soler N, Ahmad F (2009) SGLT1 is a novel cardiac glucose transporter that is perturbed in disease states. Cardiovasc Res 84: 111-118. [Crossref]

8. Norton L, Shannon CE, Fourcaudot M, Hu C, Wang N, et al. (2017) Sodium-glucose co-transporter (SGLT) and glucose transporter (GLUT) expression in the kidney of type 2 diabetic subjects. Diabetes Obes Metab 19: 1322-1326. [Crossref]

9. Solini A, Rossi C, Mazzanti CM, Proietti A, Koepsell H, et al. (2017) Sodium-glucose co-transporter (SGLT) 2 and SGLT1 renal expression in patients with type 2 diabetes. Diabetes Obes Metab 19: 1289-1294. [Crossref]

10. Wang XX, Levi J, Luo Y, Myakala K, Herman-Edelstein M, et al. (2017) SGLT2 Expression is increased in Human Diabetic Nephropathy: SGLT2 Inhibition Decreases Renal Lipid Accumulation, Inflammation and the Development of Nephropathy in Diabetic Mice. J Biol Chem 292: 5335-5348. [Crossref]

11. Marks J, Carvou N, Debnam E, Srai S, Unwin R (2003) Diabetes increases facilitative glucose uptake and GLUT2 expression at the rat proximal tubule brush border membrane. J Physiol 553: 137-145. [Crossref]

12. Lu Y, Griffen S, Boulton D, Leil T (2014) Use of systems pharmacology modeling to elucidate the operating characteristics of SGLT1 and SGLT2 in renal glucose reabsorption in humans. Front Pharmacol 5: 254.

13. Mueckler M, Thorens B (2013) The SLC2 (GLUT) family of membrane transporters. Mol Aspects Med 34: 121-138. [Crossref]

14. Uldry M, Thorens B (2004) The SLC2 family of facilitated hexose and polyo transporters. Pfugers Arch 447: 488-489. [Crossref]

15. Vallaghe J, Costy N, Morcillo V, Mathieu M, Carlson C, et al. (2016) HTRF® cell signaling platform combined with iCell® Hepatocytes: a smart solution to study insulin resistance in type 2 diabetes. Cis Bioassays.

16. Garvey W, Maianu L, Zhu J, Brechtel-Hook G, Wallace P, et al. (1998) Evidence for defects in the trafficking and translocation of GLUT4 glucose transporters in skeletal muscle as a cause of human insulin resistance. J Clin Invest 101: 2377-2386. [Crossref] 
17. Yonamine C, Pinheiro-Machado E, Michalani M, Alves-Wagner A, Esteves J, et al. (2017) Resveratrol Improves Glycemic Control in Type 2 Diabetic Obese Mice by Regulating Glucose Transporter Expression in Skeletal Muscle and Liver. Molecules 22: 1180. [Crossref]

18. Schumacher T, Benndorf RA (2017) ABC Transport Proteins in Cardiovascular Disease-A Brief Summary. Molecules 22. [Crossref]

19. Rader DJ (2006) Molecular regulation of HDL metabolism and function: implications for novel therapies. J Clin Invest 116: 3090-3100. [Crossref]

20. Mauldin J, Nagelin M, Wojcik A, Srinivasan S, Skaflen M, et al. (2008) Reduced Expression of ATP-Binding Cassette Transporter G1 Increases Cholesterol Accumulation in Macrophages of Patients with Type 2 Diabetes Mellitus. Circulation 117: 2785-2792. [Crossref]

21. Tang C, Oram J (2009) The cell cholesterol exporter ABCA1 as a protector from cardiovascular disease and diabetes. Biochimica et Biophysica 1791: 563-572. [Crossref]

22. Brunham LR, Kruit JK, Verchere CB, Hayden MR (2008) Cholesterol in islet dysfunction and type 2 diabetes. J Clin Invest 118: 403-408. [Crossref]

23. Tobin V, Le Gall M, Fioramonti X, Stolarczyk E, Blazquez AG, et al. (2008) Insulin internalizes GLUT2 in the enterocytes of healthy but not insulin-resistant mice. Diabetes 57: 555-562. [Crossref]

24. Cui XL, Schlesier AM, Fisher EL, Cerqueira C, Ferraris RP (2005) Fructoseinduced increases in neonatal rat intestinal fructose transport involve the PI3-kinase/ Akt signaling pathway. Am J Physiol Gastrointest Liver Physiol 288: G1310-1320. [Crossref]

25. Matsuzaka T, Shimano H (2011) GLUT12: a second insulin-responsive glucose transporters as an emerging target for type 2 diabetes. J Diabetes Investig 3: 130-131. [Crossref]
26. Waller A, George M, Kalyanasundaram A, Kang C, Periasamy M, et al. (2013) GLUT12 functions as a basal and insulin-independent glucose transporter in the heart. Biochimica et Biophysica Acta 1832: 121-127. [Crossref]

27. Lin W, Chuang L, Chen C, Yeh J, Hsieh P, Cheng C, Chen Y (2006) Association study of genetic polymorphisms of SLC2A10 gene and type 2 diabetes in the Taiwanese population. Diabetologia 49: 1214-1221.

28. Albrecht C, Simon-Vermont I, Elliot JI, Higgins CF, Johnston DG, et al. (2004) Leukocyte $\mathrm{ABCA} 1$ gene expression is associated with fasting glucose concentration in normoglycemic men. Metabolism 53: 17-21.

29. García-Chapa EG, Leal-Ugarte E, Peralta-Leal V, Durán-González J, Meza-Espinoza JP (2017) Genetic Epidemiology of Type 2 Diabetes in Mexican Mestizos. Biomed Res Int 2017: 3937893. [Crossref]

30. Porchay-Baldérelli I, Péan F, Emery N, Maimaitiming S, Bellili N, et al. (2009) Relationships between common polymorphisms of adenosine triphosphate-binding cassette transporter A1 and high-density lipoprotein cholesterol and coronary heart disease in a population with type 2 diabetes mellitus. Metabolism 58: 74-79. [Crossref]

31. Mather P, Pollock C (2011) Glucose Handling by the Kidney. International Society of Nephrology.

32. Cizmeci D, Arkun Y (2013) Regulatory networks and complex interactions between the insulin and angiotensin II signalling systems: models and implications for hypertension and diabetes. PLoS One 8: e83640. [Crossref]

33. Girard J (2017) Role of the kidneys in glucose homeostasis. Implication of sodiumglucose cotransporter 2 (SGLT2) in diabetes mellitus treatment. Nephrol Ther 13: 3541. [Crossref]

34. Kellett GL, Brot-Laroche E (2005) Apical GLUT2: a major pathway of intestinal sugar absorption. Diabetes 54: 3056-3062. [Crossref]

Copyright: $\mathbb{C} 2017$ Kouznetsova VL. This is an open-access article distributed under the terms of the Creative Commons Attribution License, which permits unrestricted use, distribution, and reproduction in any medium, provided the original author and source are credited. 